\title{
BIBLIOGRAFIA
}

\section{Bibliografía de y sobre Julián del Casal (1863-1893)}

OBRAS DEL AUTOR

Hojas al viento. La Habana, I89o.

Nieve. La Habana, I892.

Bustos y rimas. (Póstuma). La Habana, Biblioteca de La Habana Elegante, r893.

Nieve. Bocetos antiguos. Mi museo ideal. Cromos españoles. Marfiles viejos. La gruta del ensueño. Con estudio preliminar de Luis Urbina. México, Ed. El Intransingente, 1893.

Julián del Casal: sus mejores poemas. Editado por R. Blanco Fombona. Madrid. Ed. América, r9i6.

Selección de poesias de Julian del Casal. Introducción por Juan J. Geada y Fernández. La Habana, Colección de Libros Cubanos, I93I.

Poesias completas. Ensayo preliminar y notas de Mario Cabrera Saqui. La Habana, Dirección de Cultura del Ministerio de Educación, I945.

Selected Prose of Juliain del Casal. Selección y prefacio de Marshall $\mathrm{E}$. Nunn. University of Alabama Press, I949.

Crónicas Habaneras. Compilación e introducción de Angel Augier, prólogo de Samuel Feijoó. Las Villas, Dirección de publicaciones Universidad Central de Las Villas, I963.

Prosas, 3 vols. Edición del Centenario. La Habana, Consejo Nacional de Cultura, r963, I964. 
Poesías. Edición del Centenatio. La Habana, Consejo Nacional de Cultura, 1963.

\section{OBRAS SOBRE EL AUTIOR}

Acosta, Agustín. "Evocación de Julián del Casal". Revista cubana, XIX (enero-junio, r945).

Augier, Angel. "Evocación de Casal". Mensuario de arte, literatura, bistoria y critica. I, No. II (octubre, I950).

—.. "Julián del Casal". Universidad de La Habahna. Nos. 50-5I (septiembre-diciembre, r943) I33-I44.

Balseiro, José A. "Cuatro enamorados de la muerte en la lírica hispanoamericana". Expresión de Hispanoamérica. San Juan de Puerto Rico, Instituto de cultura puertorriqueña, vol. I, I960.

Baquero, Gastón. "Panorama: entrada al otoño y un recuerdo de Casal". Diario de la Marina. La Habana (septiembre 23, 1945).

Borrero Echeverría, Esteban. "El lirio de Salomé". El Fígaro. La Habana (octubre 22 de I899).

Borrero, Dulce María. "Poesía a Julián del Casal". El Fígaro (octubre 27$, r 912$)$.

Carbó, Sergio. "Julián del Casal". Prensa Libre. La Habana (octubre 2 I, I943).

Chacón, Francisco. "Notas de mi cartera". El Fígaro (noviembre 26, r885).

Chacón y Calvo, José M. "En torno a un epistolario de Julián del Casal". Boletin de la Academia Cubana de la Lengua. VII, Nos. 3-4 (juliodiciembre, 1958) 346-373.

Cabrera Saqui, Mario. "Julián del Casal y el Modernismo". Revista Bimestre Cubana (enero-febrero, r946) 28-53.

Caillet-Bois, Julio. "Julián del Casal". Realidad, revista de ideas. Buenos Aires (marzo-abril, I947) 282-287.

Conde Kostia (Aniceto Valdivia). "Julián del Casal". El Fígaro (noviembre 7, I897).

Darío, Rubén. "Carta abierta a Enrique Hernández Miyares". La Habana Elegante (junio 17,1894 ).

-. Páginas de arte. Madrid, I924.

De Armas, José. Estudios y retratos. Madrid, I9I r.

De Carricarte, Arturo R. "Casal", El Fígaro (octubre 27, IgI2), 
De la Cruz, Manuel. "Artículo necrológico". La Habana Elegante (octubre, I893).

- Cromitos cubanos. Madrid, Calleja, I926.

Del Monte, R. "Mi deuda". La Habana Elegante (octubre 29, I893).

Duplessis, Gustavo. "Julián del Casal". Revista Bimestre Cubana, LIV (julio-agosto) (septiembre-octubre) (noviembre-diciembre, I944), 3I-75, I 40-I 70, 243-286.

Ducazcal (Joaquín Navarro Riera). "Julián del Casal". Prosa y verso, semanario literario. Santiago de Cuba (octubre 20, 1894).

—. "Astro sin eclipse: Julián del Casal". Horizontes. La Habana, I932.

Estenger, Rafael. "Con la hermana de Juliản del Casal". Bobemia, revista cubana (mayo 7, I950), 36-37, 106-107.

-... Los amores de cubanos famosos. La Habana, I939.

-. "José A. Silva y Calibán sonríe (recuerdos inéditos de Casal)". Cuba Contemporáned, XXIII (I920), $3^{\mathrm{I}-44}$.

Fernández de Castro, José A. "Aniversario y revisión de Casal". Revista de La Habana, I, No Io (1930), 5 I-56.

Figueroa, Esperanza. "Julián del Casal y Rubén Darío". Revista Bimestre Cubana, L, No 2 (I942).

- "Revisión de Julián del Casal". Trabajos del Primer Congreso Nacional de Historia, 1942. La Habana, I943.

- . "Apuntes sobre Casal". Revista Iberoamenicana, VII (febrero, I944), I9I-208.

—. "Julián del Casal y el modernismo". Revista Iberoamericana, XXXI. No 59 (junio, r965), 47-69.

Gálvez, Wen. "Nieves". El Fígaro (junio I2, I892).

- . "La obra póstuma de Casal". El Fígaro (febrero 8, 1893).

Geada y Fernández, Juan J. Julián del Casal La Habana, Cultural, S. A., I93I.

—. "Influencia de Casal en la literatura castellana". Revista de Oriente, II, No 22. Santiago de Cuba (I930).

Geada de Prulletti Rita. "El sentido de la evasión en la poesía de Julián del Casal". Revista Iberoamericana, XXXII, No 6 I (enero-junio, I 966), IOI-I08.

González, Manuel Pedro: "Un notable estudio argentino sobre Julián del Casal. Glosa de aniversario". Revista Iberoamericana XIX, No 38 (septiembre I954). 253-260.

Henríquez Ureña, Pedro. "Ante la tumba de Cașal". El Figaro (octubre 25, I9I4). 
Heredia, Nicolás. Trozos selectos, $2^{\mathfrak{a}}$ edición. La Habana, 1908.

-.. Puntos de vista. La Habana, I892.

Hernández Miyares, Enrique. "Prosas". Obras completas, III. La Habana, rgr6.

—. "Homenaje a Julián del Casal". La Habana Elegante. (1893).

Lezama Lima, José. "Julián del Casal". El Mundo. La Habana (junio I5, I94I).

Loynaz de Alvarez Cañas, Dulce M. "Ausencia y presencia de Julián del Casal". Boletin de la Academia Cubana de la Lengua, V, Nos. r-4, 5-26.

Malpica, Domingo. "Nota biográfica". La Habana Elegante (octubre 29, 1893).

Márquez Sterling, Manuel. "Julián del Casal". Revista Azul. II.

—. "El espíritu de Casal". El Fígaro (octubre 26, I902).

Martí, José. "Julián del Casal". Obras completas. No r3. La Habana, Trópico, I938, págs. II-I3. También en: Obras completas, I. La Habana, Lex, 1946. Y en: Patria. New York (octubre 3I, I893). - Hombres. La Habana, I906.

Morales Gómez, Julio. Julián del Casal. La Habana, I932.

Morpay, Manuel. "En honor de Casal". El hogar. La Habana, $N^{9} 38$ (noviembre I2, 1893), 4 .

Moner Sans, José María. "La iniciación poética de Julián del Casal". Atenea (marzo, I948), 214-222.

- Julián del Casal y el modernismo bispanoamericano. México, 1952.

—. "Los temas poéticos de Julián del Casal". Cuaddernos Americanos. XLIX, No I (enero-febrero, I950), 246-260.

- Julián del Casal. México, I953.

Montoro, Rafael. "Recuerdos e impresiones". La Habana Elegante (octubre 29, 1893).

Nunn, Marshall. "Juliản del Casal, First Modernist Poet". Hispania (febrero, 1940 ), 73-80.

- Life and Works of Julián del Casal. Illinois, Urbana, I939.

Padilla, Carlos Luis. "A Julián del Casal". El hogar, No 37 (noviembre $5,1893)$.

Pichardo, Manuel Serafín. "Elegía a Julián del Casal". El Fígaro (octubre 29, 1893).

Poncet, Carmen. "Dualidad de Casal". Revista Bimestre Cubana, LIII № 3 (mayo-junio, I944), I93-212.

Portuondo, José Antonio. "Angustia y evasión de Julián del Casal". Cuadernos de historia habanera. La Habana, No I3 (1937). 
Poveda, José Mànuel. "Julián del Casal". El Fígaro (noviembre II, I926).

Prulletti, Rita Geada. "El sentido de la evasión en la poesía de Julián del Casal". Revista lberoamericand, XXXII, No 6I (enero-junio, I966), IOI-I08.

Roa García, R. "Ensayo sobre Julián del Casal". Diario de la Marina. La Habana (enero 3, r926).

Saíz de la Mora, Jesús. "Julián del Casal". Revista Habanera (mayo, I9I4).

Sanguily, Manuel. Hojas literarias. II, La Habana (octubre 3I, I893).

Sos, Ciriaco. Julión del Casal: un falsario de la rima. La Habana, 1893.

Schulman, Ivan A. "Las estructuras polares en la obra de José Martí y Julián del Casal". Revista Iberoamericana. XXIX, No 56 (juliodiciembre, 1963); 25 I-282.

Varona, Entique José. Revista cubana. XI (I890), 473-477, XVI (1892), I $42-146$ y XVIII (1893).

Villoch, Federico. "Viejas postales descoloridas. La celda de Casal". Diario de la Marina (marzo 30 , I94I).

Vitier, Medardo. Apuntaciones literarids. La Habana, I935.

\section{BIBLIOGRAFIA GENERAL ${ }^{1}$}

Argüello, Santiago. Modernismo y modernistas. Guatemala, C. A. Tipografía Nacional, I935.

Bueno, Salvador. Contorno del modernismo en Cuba. La Habana, I95o.

Blanco Fombona, Rufino. El modernismo y los poetas modernistas. Madrid, I929.

Carbonell y Rivero, José Manuel. "La poesía lírica en Cuba". Evolución de la cultura cubana (I608-I927), vol. IV, La Habana, I928.

Chacón y Calvo, José M. Las cien mejores poesias cubanas. Madrid, Cultura Hispánica, I958, pp. 295-296.

Codina, Carlos. Las letras cubanas. La Habana, I9I7.

Estenger, Rafael. Caracteres constantes de las letras cubanas. La Habana, I954.

1 Casal aparece incluido en casi todas las historias y antologías generales de la literatura hispanoamericana. Como estas fuentes son las más asequibles, nos hemos limitado a no citarlas. En cuanto a lo publicado dentro de Cuba últimamente, tenemos noticias sólo de lo citado. 
Fernández de Castro, José A. Esquema bistórico de las letras cubanas. La Habana, r949.

Fernández de la Vega, Oscat \& Carvajal y Bello, Juan F. Literatura cubana. Español IV curso. La Habana, Selecta, I960, págs. 352-36r.

García Prada, Carlos. Poetas modernistas bispanoamericanos (Antología), Madrid, Cultura Hispánica, I956, págs. 89-97.

Gullón, Ricardo. Direcciones del módernismo. Madrid, Gredos, r963.

Henríquez Ureña, Max. Panorama bistórico de la literatura cubana. III vols. New York, Las Américas Publishing Co., I963.

- Tablas cronológicas de la literatura cubana. Santiago de Cuba, I929.

—. Breve historia del modernismo. México, Fondo de Cultura Económica, 1954 .

Henríquez Ureña, Pedro. Ensayos críticos. El modernismo en la poesia cubana. La Habana, I905. También en: Obra crítica. Biblioteca Americana, Serie de Literatura Moderna, México-Buenos Aires, Fondo de Cultura económica, I960, págs. 17-22.

Julio, Silvio. Escritores antillanos. Río de Janeiro, Livraria H. Antunes, I944.

Lazo, Raimundo. La teoria de las generaciones y su aplicación al estudio bistórico de la literatura cubana. La Habana, 1954.

- Reseña de la bistoria cultural de Cuba. Buenos Aires, Jackson, I 948.

Meza Fuentes, Roberto. De Díaz Mirón a Rubén Dario. Santiago de Chile, I940.

Piedra-Bueno, Andrés. Literatura cubana. Sintesis histórica. La Habana, I 945 .

Remos y Rubio, Juan'J. Restmen de bistoria de la literatura cubana. La Habana, I930.

_- Historid de la literatura cubana. Vol. III .La Habana, Cárdena y Co., I945.

- Proceso histórico de las letras cubanas. Madrid, Guadarrama, 1958.

—. "Los albores del modernismo en Cuba". Micrófono. La Habana (I937), 236-244.

Salazar y Roig, Salvador. El dolor en la lírica cubana. La Habana, 1925. . Historia de la literatura cubana. La Habana, Avisador Comercial, 1925.

Silva Uzcátegui, R. D. Historia crítica del modernismo en la literatura castellana. Barcelona, I925. 
Torres-Rioseco, Arturo. Precursores del modernismo. Madrid, r925.

- Precursores del modernismo, estudio critico y antologia. New York, Las Américas Pub., Co., I963.

Valle, Adrián del. El parnaso cubano. Barcelona, I907.

Vitier, Cynthio. Lo cubano en la poesía. La Habana, Departamento de Relaciones Culturales, I958.

Rita Geada de Prullettit

Southern Connecticut State College 
